\title{
Risk of Microvascular Anastomosis Performed in Previous Treated Neck
}

\author{
Se Jin Hyun $(D)$ and Soon-Hyun Ahn (D) \\ Department of Otorhinolaryngology-Head and Neck Surgery, Seoul National University College of Medicine, \\ Seoul National University Hospital, Seoul, Korea
}

치료력이 있는 경부에서 시행되는 미세문합술의 안정성

현세진 · 안순현

서울대학교 의과대학 서울대학교병원 이비인후-두경부외과학교실

\author{
Received August 14, 2020 \\ Revised October 19, 2020 \\ Accepted October 24, 2020 \\ Address for correspondence \\ Soon-Hyun Ahn, MD, PhD \\ Department of Otorhinolaryngology- \\ Head and Neck Surgery, \\ Seoul National University Hospital, \\ 101 Daehak-ro, Jongno-gu, \\ Seoul 03080, Korea \\ Tel +82-2-2072-3649 \\ Fax $+82-2-735-2387$ \\ E-mail ahnsh30@snu.ac.kr
}

Background and Objectives This study aimed to determine if a microvascular anastomosis on the neck, which had previously been treated, increases the risk of early complications, such as flap failure or hemorrhage and venous congestion that necessitates re-exploration. Subjects and Method A retrospective review was conducted on 274 cases of tumor resection with simultaneous free flap reconstruction from 2005 to 2019. Flap failure and re-exploration rate was evaluated according to the clinical variables including treatment history of recipient vessels.

Results Twenty-one (7.7\%) cases of flap failure were identified and re-exploration was conducted in $51(18.6 \%)$ cases. Although the failure rate appeared to be high when micro-anastomosis was performed in the neck, where neck dissection with radiotherapy was previously performed $(22.7 \%)$, there was no statistical significance compared with no previous treatment group. Previous neck dissection with irradiation was found to influence re-exploration \{odds ratio $(\mathrm{OR})=3.674[95 \%$ confidence interval $(\mathrm{CI}) 1.348-10.014, p=0.011]\}$ compared to no treatment. However, previous radiotherapy or surgery only did not show any significant difference compared to the untreated group. Venous congestion was the most common cause of re-exploration $(50.1 \%)$, followed by hematoma $(33.3 \%)$, and previous neck dissection with radiotherapy increased the risk of both [OR for venous congestion=3.056 (95\% CI 1.009-9.255)], $p=0.048$, OR for hematoma $=6.286(95 \%$ CI $1.679-23.526), p=0.006]$ compared with no previous treatment. Radiotherapy alone did not change the risk of early complication.

Conclusion Micro-anastomosis in a previously treated neck is feasible in terms of flap failure. However, micro-anastomosis in a neck, where neck dissection with radiotherapy were performed, may be more likely to cause complications such as venous congestion and hematoma that necessitate re-exploration.

Korean J Otorhinolaryngol-Head Neck Surg 2021;64(11):811-9

Keywords Failure; Free flap; Microvascular anastomosis; Reoperation; Salvage.

\section{Introduction}

Concurrent chemoradiation therapy (CCRT) or organ pre-

This is an Open Access article distributed under the terms of the Creative Commons Attribution Non-Commercial License (https://creativecommons.org/licenses/by-nc/4.0) which permits unrestricted non-commercial use, distribution, and reproduction in any medium, provided the original work is properly cited. serving surgery with adjuvant treatment have been frequently used as an initial treatment in head and neck cancer, ${ }^{1,2)}$ because of better functional outcome and a lower rate of acute complications than radical surgery. ${ }^{3)}$ However, with the increase of CCRT or organ preserving surgery, salvage surgery after failure of initial treatment is increasing and surgery is 
becoming more important for the treatment of recurrent or residual cancer. ${ }^{4)}$ Wide excision to achieve clear margins is important not only in primary but also in salvage surgery, and free flap surgery is the gold standard in the reconstruction of large surgical defects. Although the overall success rate of free flaps in the head and neck is known to be high, ${ }^{5-9)}$ microvascular anastomosis in a previously treated neck will be technically more difficult to accomplish than normal condition but increasingly required for recurrent or residual cancer. When the flap's survival is uncertain, rapid re-exploration is important. The overall unplanned reoperation rates after free flap surgery are known to range from $18.0 \%$ to $20.0 \%{ }^{10-14)}$ and there are cases where free flaps are rescued through re-exploration, but there are cases where the rescue fails and the flaps are finally lost. The overall unplanned reoperation rates after free flap surgery are known to range from $18.0 \%$ to $20.0 \%,{ }^{10-14)}$ but there is a lack of accurate analysis of the risk of early complications, such as hemorrhage or venous congestion that necessitate immediate re-exploration, when microvascular anastomosis is performed in the neck where previous treatments such as radiation therapy (RT) or surgery have been performed. Given that unplanned reoperation for flap salvage is a burden to patients and surgeons and result in a prolonged hospital stay and increased health care costs, the identification of risk factors of flap failure or re-exploration is important for treatment. Previous studies have shown that reoperation after free flap surgery is associated with comorbidities such as smoking, hypertension, and prolonged operation time. ${ }^{10-14)}$ In addition, the direct causes of reoperation and failure of free flaps include thrombosis, and the most important factor in the development of thrombosis is the technical ability of the surgeon. ${ }^{8,15)}$ There have been study on the effects of previous treatment on flap outcome through comparison between salvage surgery and primary surgery, there was no statistically significant effect. ${ }^{16)}$ But no studies have subdivided the previous treatment, the risk of performing microvascular anastomosis in the context of previous RT or surgery was not analyzed. As such, the aim of this study is to identify the risk factors for early complications, such as flap failure and re-exploration, and causes that required re-exploration after the microvascular anastomosis, especially previous treatments such as neck dissection or RT, using a single surgeon's data.

\section{Subjects and Methods}

\section{Patients}

This study constituted a retrospective review of consecutive cases where tumor resection and free flaps are performed simultaneously in the head and neck between January 2005 and August 2019. All surgeries were performed by a single surgeon. We excluded patients younger than 18 years and those who underwent tumor resection and free flap reconstruction more than twice. Patient characteristics, perioperative data, and re-exploration data were collected from the medical records. Patient characteristics and perioperative data included patient age, sex, cardiovascular disease, diabetes mellitus, smoking, body mass index (BMI), reconstruction site, donor site, previous irradiation, history of surgery at the anastomosis site, size of the removed mass, operation time, and cause of re-exploration. The Institutional Review Board of Seoul National University approved this retrospective study of medical records (IRB No. H-2002-076-1101).

The patients were grouped according to the previously treated condition of site of recipient vessels used for anastomosis, not by the previously treated condition of the reconstruction site. Even if the free flap was performed in salvage cases, if the microvascular anastomosis is performed in the context of no previous treatment, like contralateral neck or superficial temporal or external carotid which is higher than previous treatment field or internal mammary artery which is lower than treatment field is regarded as surgery in the field of no previous treatment. Patients were categorized into groups based on BMI according to the World Health Organization's definition of overweight and obese $\left(>25.0 \mathrm{~kg} / \mathrm{m}^{2}\right)$. Primary tumor site was categorized into oral cavity and oropharynx including salivary gland origin cancers (buccal, alveolar ridge, retromolar trigon, floor of mouth, palate, tongue, tonsil, posterior pharyngeal wall, mandible), larynx and hypopharynx and esophagus, maxilla (maxilla, sinus), ear (external auditory canal and auricle). Because it was a retrospective study, we could not get accurate data on free flap size. Instead, the size of the surgical specimen of the primary tumor was used. The duration of operation was categorized as less than either 12 hours or greater than 12 hours.

\section{Statistical analysis}

Univariate analyses were performed using the chi-squared and Fisher's exact tests to correlate outcomes and categorical variables. All free flaps performed in each patient were ana- 
lyzed independently. All perioperative variables were analyzed for a correlation with flap failure and re-exploration. Variables with $p \leq 0.05$ on univariate analyses were included in the multiple logistic regression analysis. $p$-values $<0.05$ were considered statistically significant. All calculations were performed using SPSS ver. 13.0 (SPSS Inc., Chicago, IL, USA).

\section{Results}

\section{Outcome of free flap}

A total of 274 patients who underwent simultaneous tumor resection and free flap reconstruction surgery of the head and neck were included. Fig. 1A shows the number of cases per year and the increasing number and proportion of cases of previous treatment such as neck dissection or RT at the anastomosis site. Free flap failure occurred in 21 cases $(7.7 \%)$, and in 6 cases $(8.7 \%)$ of 69 patients who had previously undergone neck dissection or radiotherapy at the anastomosis site, and 15 (7.3\%) of 205 patients who had not received previous treatment at the anastomosis site. Re-exploration was performed in 51 cases (18.6\%); 20 cases (29.0\%) of 69 patients who had previously received neck dissection or RT at the anastomosis site and 31 (15.1\%) of 205 patients who had not received previous treatment at the anastomosis site. In the year when there was a lot of microvascular anastomosis in the site where surgery or radiotherapy had previously been performed, there was a tendency that reoperation was performed more frequently (Fig 1B). The demographic data of patients in the untreated and previously treated group are shown in Table 1 and the patients in the previously treated group showed a lower rate of overweight or smoking. And more larynx, hypopharynx or esophagus patients were included. A total of 69 patients had previous treatment history at the site of the microvascular anastomosis. Among them, 52.2\% received radiotherapy, $15.9 \%$ received neck dissection, and $31.9 \%$ received both radiotherapy and neck dissection.

\section{Variables related to free flap failure or re-exploration}

Free flap failure occurred in 21 of the 274 cases in total (7.7\%). No significant correlation was found between demographics, comorbidities, reconstruction site and flap failure (Table 2). Analysis according to the donor site showed that failure of radial free forearm free flap did not occur at all and the failure rate was higher in the case of reconstruction with a flap that is rarely used like scapular, iliac crest, and rectus abdominis flap. Although the failure rate appeared higher in microvascular anastomosis in patients previously treated both by neck dissection and RT (22.7\%) than other groups (0-7.3\%), there was no statistically significant difference according to the previous treatment at the anastomosis site $(p=0.053)$.

Of the 274 patients, 51 underwent re-exploration after free flap reconstruction because of the risk of flap compromise. The results of the univariate analysis of variables related to
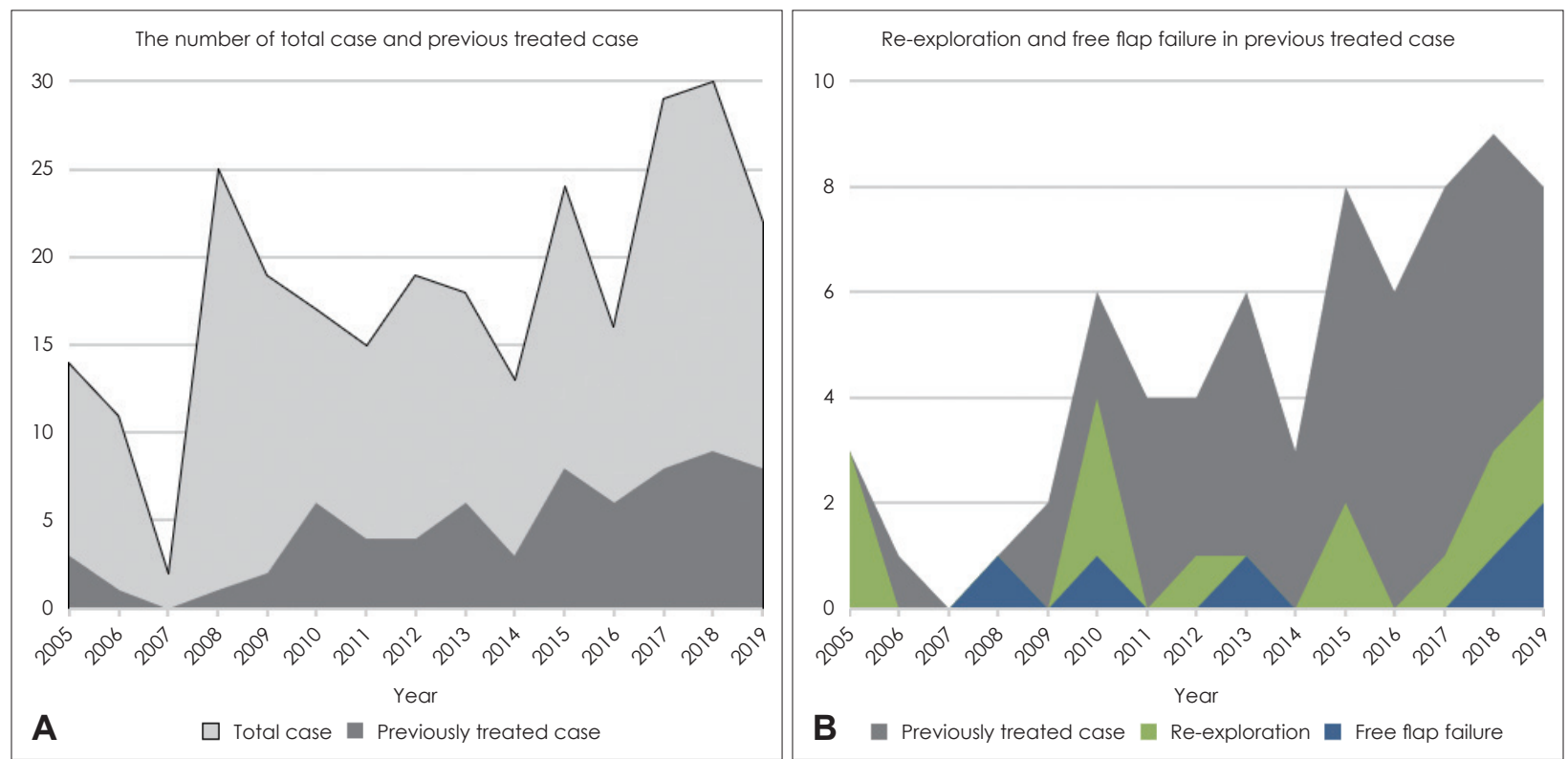

Fig. 1. Cases per year. Total number of free flap cases and microvascular anastomosis in previously treated neck (A), Number of microvascular anastomosis in previous treated neck, Re-exploration, and flap failure per year (B). 
Table 1. Demographic according to the treatment history of neck where micro-anastomosis is performed

\begin{tabular}{|c|c|c|c|}
\hline Variables & Untreated neck $(n=205)$ & Previously treated neck $(n=69)$ & p-value \\
\hline Mean age (range) & $59(23-85)$ & $61(20-75)$ & 0.160 \\
\hline Male:female & $146: 59$ & $55: 14$ & 0.168 \\
\hline $\mathrm{BMI}>25$ & $52(25.4)$ & $9(13.0)$ & 0.033 \\
\hline Current smoker & $35(17.1)$ & $4(5.8)$ & 0.020 \\
\hline \multicolumn{4}{|l|}{ Systemic disease } \\
\hline Cardiovascular disease & $78(38.0)$ & $18(26.1)$ & 0.072 \\
\hline Diabetes & $40(19.2)$ & $11(16.0)$ & 0.510 \\
\hline Primary lesion & & & 0.026 \\
\hline Oral cavity, salivary gland, oropharynx & $160(78.0)$ & $47(68.1)$ & \\
\hline Larynx, hypopharynx, esophagus & $27(13.2)$ & $19(27.5)$ & \\
\hline Maxilla & $12(5.8)$ & $3(4.3)$ & \\
\hline Ear & $6(2.9)$ & $0(0.0)$ & \\
\hline Pathology & & & 0.676 \\
\hline SCC & $172(83.9)$ & $62(89.9)$ & \\
\hline Salivary origin (MEC, ACC, AdC) & $19(9.2)$ & $3(4.3)$ & \\
\hline Sarcoma & $5(2.4)$ & $1(1.4)$ & \\
\hline Others & $9(4.4)$ & $3(4.3)$ & \\
\hline Tumor classification & & & 0.072 \\
\hline $\mathrm{T} 1$ or $\mathrm{T} 2$ & $108(52.7)$ & $27(39.1)$ & \\
\hline $\mathrm{T} 3$ or T4 & $91(44.4)$ & $37(53.6)$ & \\
\hline Unspecific & $6(2.9)$ & $5(7.2)$ & \\
\hline \multicolumn{4}{|l|}{ Previous treatment } \\
\hline RT/CCRT & & $36(52.2)$ & \\
\hline Neck dissection & & $11(15.9)$ & \\
\hline Neck dissection with RT/CCRT & & $22(31.9)$ & \\
\hline
\end{tabular}

Data are presented as $\mathrm{n}$ (\%). BMl: body mass index, SCC: squamous cell carcinoma, MEC: mucoepidermoid carcinoma, ACC: adenoid cystic carcinoma, AdC: adenocarcinoma, RT: radiation therapy, CCRT: concurrent chemoradiation therapy

re-exploration are listed in Table 2. The rate of re-exploration was significantly higher in patients in whom microvascular anastomosis was performed in the context of previous treatment ( $p=0.004)$, size of the resected tumor greater was than $10 \mathrm{~cm}$ in largest diameter $(p=0.001)$ and the operation time exceeded 12 hours ( $p=0.003$ ). Subsequently, the multiple logistic regression analysis showed that more than 12 hours of surgery \{odds ratio $(\mathrm{OR})=2.648[95 \%$ confidence interval $(\mathrm{CI})$ $1.256-5.737, p=0.014]\}$ and neck dissection with $\mathrm{RT}$ [OR= $3.674(95 \%$ CI 1.348-10.014, $p=0.011)]$ at the anastomosis site were independent risk factors for re-exploration (Table 3). The risk of re-exploration or flap failure in patients who received only one treatment, either radiotherapy or surgery, showed no difference when compared with no previous treatment group.

\section{Causes of re-exploration}

Venous congestion was the most common cause of re-exploration (26 cases, 50.1\%), followed by hematoma (17 cases, $33.3 \%$ ). Salvage surgery was successful in $53.8 \%$ of cases of venous congestion and $88.2 \%$ of cases of hematoma (Table 4 ). In the univariate analysis for the risk of each complication, venous congestion showed a tendency to occur more frequently in patients whose microvascular anastomoses were performed in previously operated terrain, with or without RT $(22.7 \%$ in with RT, $18.2 \%$ without RT); but showed statistically borderline significance $(p=0.050)$. The arterial crisis showed no statistical relationship with any variable and hematoma occurred more frequently in female and in cases where microvascular anastomosis was performed on previously treated terrain and resected mass greater than $10 \mathrm{~cm}$ in largest diameter (Table 5). In the logistic regression analysis, previous neck dissection with irradiation at the anastomosis site increased the risk of venous congestion $[\mathrm{OR}=3.056(95 \%$ CI 1.009-9.255, $p=0.048)$ ] and hematoma $[\mathrm{OR}=6.286(95 \% \mathrm{CI} 1.679-23.526, p=0.006)]$ compared to no previous treatment. In addition, previous neck dissection only group at the anastomosis site also showed a higher risk of hematoma $[\mathrm{OR}=6.286(95 \%$ CI 1.140-34.699, $p=$ $0.035)$ ] compared to the no previous treatment group (Table 6). 
Microvascular Anastomosis in Previous Treated Neck I Hyun SJ, et al.

Table 2. Univariative analysis of factors for free flap failure and re-exploration

\begin{tabular}{|c|c|c|c|c|}
\hline \multirow{2}{*}{ Variables } & \multicolumn{2}{|c|}{ Flap failure $(n=21)$} & \multicolumn{2}{|c|}{ Re-exploration $(n=51)$} \\
\hline & $\mathrm{n}(\%)$ & p-value & $\mathrm{n}(\%)$ & $p$-value \\
\hline Age & & 0.765 & & 0.445 \\
\hline$\leq 60(n=126)$ & $9(7.1)$ & & $21(16.7)$ & \\
\hline$>60(n=148)$ & $12(8.1)$ & & $30(20.3)$ & \\
\hline Sex & & 0.760 & & 0.121 \\
\hline Male $(n=201)$ & $16(8.0)$ & & $33(16.4)$ & \\
\hline Female $(n=73)$ & $5(6.8)$ & & $18(24.7)$ & \\
\hline BMI & & 0.480 & & 0.810 \\
\hline $\mathrm{BMI}>25(\mathrm{n}=61)$ & $4(6.6)$ & & $12(19.7)$ & \\
\hline $\mathrm{BMI} \leq 25(\mathrm{n}=213)$ & $17(8.0)$ & & $39(18.3)$ & \\
\hline Current smoker (in 28 days) & & 0.161 & & 0.223 \\
\hline Yes $(n=39)$ & $5(12.8)$ & & $10(34.4)$ & \\
\hline No $(n=235)$ & $16(6.8)$ & & $41(17.4)$ & \\
\hline Cardiovascular disease & & 0.154 & & 0.488 \\
\hline Yes $(n=96)$ & $10(10.4)$ & & $20(20.8)$ & \\
\hline No $(n=178)$ & $11(6.2)$ & & $31(17.4)$ & \\
\hline Diabetes & & 0.211 & & 0.844 \\
\hline Yes $(n=51)$ & $2(3.9)$ & & $9(17.6)$ & \\
\hline No $(n=223)$ & $19(8.5)$ & & $42(18.8)$ & \\
\hline Reconstruction site & & 0.086 & & 0.253 \\
\hline Oral cavity, oropharynx $(n=207)$ & $14(6.8)$ & & $40(19.3)$ & \\
\hline Larynx, hypopharynx, esophagus $(n=46)$ & $3(6.5)$ & & $6(13.0)$ & \\
\hline Maxilla $(n=15)$ & $4(26.7)$ & & $5(33.3)$ & \\
\hline Ear $(n=6)$ & $0(0)$ & & $0(0)$ & \\
\hline Donor site & & 0.069 & & 0.110 \\
\hline $\operatorname{ALTF/RFFF}(n=191)$ & $10(5.2)$ & & $29(15.2)$ & \\
\hline Fibular/scapular/iliac crest flap ( $n=62)$ & $8(12.9)$ & & $16(25.8)$ & \\
\hline LD/rectus abdominis flap $(n=19)$ & $3(14.3)$ & & $6(31.6)$ & \\
\hline Jejunal flap (n=2) & $0(0)$ & & $0(0)$ & \\
\hline Previous treatment at anastomosis site & & 0.053 & & 0.004 \\
\hline No $(n=205)$ & $15(7.3)$ & & $31(15.1)$ & \\
\hline RT/CCRT only $(n=35)$ & $1(2.8)$ & & $6(16.7)$ & \\
\hline Neck dissection only $(n=11)$ & $0(0)$ & & $4(36.4)$ & \\
\hline Neck dissection with RT/CCRT $(\mathrm{n}=22)$ & $5(22.7)$ & & $10(45.5)$ & \\
\hline Operation time (hour) & & 0.090 & & 0.003 \\
\hline$>12$ hours $(n=43)$ & $6(14.0)$ & & $15(34.9)$ & \\
\hline$\leq 12$ hours $(n=231)$ & $15(6.5)$ & & $36(15.6)$ & \\
\hline Removed mass (large diameter) & & 0.455 & & 0.001 \\
\hline$>10 \mathrm{~cm}(\mathrm{n}=32)$ & $3(9.4)$ & & $13(40.6)$ & \\
\hline$\leq 10 \mathrm{~cm}(\mathrm{n}=242)$ & $18(7.4)$ & & $38(15.7)$ & \\
\hline
\end{tabular}

BMI: body mass index, ALTF: anterolateral thigh flap, RFFF: radial forearm free flap, LD: latissimus dorsi flap, RT: radiation therapy, CCRT: concurrent chemoradiation therapy

\section{Discussion}

CCRT and organ preserving surgery with adjuvant treatment have been preferred as initial treatment because they outperform radical surgery in functional outcomes and complications. ${ }^{1-3)}$ As a result, more cases of salvage surgery are required, and the number of cases of salvage surgery seems to be also increasing in this study, and microvascular anastomosis at sites which had previously undergone neck dissection and/or RT are likely to lead to early complications and re-exploration. In our study, the overall free flap success rate was $92.3 \%$, which is similar to the previous literature reports, which range from 
Table 3. Multiple logistic regression analysis of factors for re-exploration

\begin{tabular}{lccc}
\hline \multicolumn{1}{c}{ Variable } & Adjusted OR & $95 \% \mathrm{Cl}$ & Adjusted p-value \\
\hline Operation time (hour) $>12 \mathrm{hrs}$ & 2.648 & $1.256-5.737$ & 0.014 \\
Removed mass (large diameter) $>10 \mathrm{~cm}$ & 2.231 & $0.916-5.438$ & 0.077 \\
Previous treatment at anastomosis site & & & \\
No & Reference & & 0.858 \\
RT/CCRT only & 1.093 & $0.411-2.907$ & 0.294 \\
Neck dissection only & 2.116 & $0.522-8.569$ & 0.011 \\
Neck dissection with RT/CCRT & 3.674 & $1.348-10.014$ & \\
\hline
\end{tabular}

RT: radiation therapy, CCRT: concurrent chemoradiation therapy, OR: odds ratio, Cl: confidence interval

Table 4. Causes of re-exploration

\begin{tabular}{lccr}
\hline \multicolumn{1}{c}{ Cause } & $\begin{array}{c}\text { Number of } \\
\text { cases }\end{array}$ & Salvage (\%) & Failure (\%) \\
\hline Venous congestion & 26 & $14(53.8)$ & $12(46.2)$ \\
Arterial crisis & 8 & $1(12.5)$ & $7(87.5)$ \\
Hematoma & 17 & $15(88.2)$ & $2(11.8)$ \\
Total & 51 & $30(58.8)$ & $21(41.2)$ \\
\hline
\end{tabular}

$85 \%$ to $98 \%{ }^{5-9)}$ Up to $18.6 \%$ of patients underwent a re-exploration after free flap reconstruction, which is also similar to reoperation rate in free flap reconstruction surgery of head and neck reported by previous studies. ${ }^{11,12)}$ Previous studies have shown that several factors are associated with reoperation and free flap failure, such as previous treatment at the anastomosis site, cardiovascular diseases such as hypertension, angina pectoris, arteriosclerosis, and diabetes. ${ }^{8,10,13,15)}$ However, in the head and neck, few authors have confirmed that the previous treatment is a risk factor for re-exploration after free flap reconstruction. ${ }^{11,14)}$ The identification of the risk of performing microvascular anastomosis in previously treated neck can help surgeons better consult with patients and make such risks predictable. In the present study we analyzed the free flap reconstruction performed by a single surgeon to reduce the bias due to the differences between surgeons.

Many medical factors, such as comorbidities including cardiovascular disease, diabetes, obesity, and smoking history, may influence re-exploration and flap success. ${ }^{17,18)}$ However, in the present study, there was no significant correlation between age, sex, cardiovascular disease, diabetes mellitus, smoking, obesity, and re-exploration and free flap failure.

There have been some papers that compared the success rate of free flaps by donor site. Nakatsuka, et al. ${ }^{19)}$ have shown that flap survival rate for radial forearm, rectus abdominis, and jejunum flaps is significantly better than that of other flaps in a series of 2372 head and neck free flap reconstructions. However, Zhou, et al. ${ }^{20)}$ have concluded that there is statistically significant difference between the success rates in fibula flap, anterolateral thigh flap, and radial forearm flap groups. In our series, reconstruction with a flap that is rarely used like scapular, iliac crest and rectus abdominis flaps had higher failure and re-exploration rates and the surgeon's familiarity for the flap may be an important factor influencing flap failure or re-exploration. Also, our analysis showed that surgery duration of more than 12 hours was an independent risk factors for re-exploration [OR=1.253 (95\% CI 1.253-6.666, $p=0.013)]$. A prolonged anesthesia may set off a longer tissue ischemia, resulting in anoxic injuries. ${ }^{21)}$ Prolonged anesthesia also requires more fluid supply during surgery. Large amounts of crystalloid supplies during surgery also are associated with free flap complications. ${ }^{22)}$ Wong, et al. ${ }^{23)}$ have concluded that operative time is also significantly associated with increased risk for free flap failure in a study including 778 free flap operations. However, the prolonged operation time in this series may mean surgery with larger resection and complex reconstruction as these data are from a single surgeon and the meaning may be that difficult surgeries have a higher risk of re-exploration.

The main focus of this research was the effect of previous treatment in the field of microvascular anastomosis. As the RT is used frequently as primary treatment in many head and neck cancers, the influence of RT on the microvascular anastomosis became an issue in salvage surgeries. Radiotherapy is known to causes damage to blood vessels, which can cause blood flow reduction and thrombus formation and affect the outcome of the flap. ${ }^{24)}$ However the effect of previous irradiation at the anastomosis site on free flap failure remains controversial. Significant correlations between flap failures and previous RT in excess of total 60 Gy have been reported, ${ }^{25-27)}$ but a study by Zhao, et al. ${ }^{14)}$ did not confirm the statistical relationship between radiotherapy within 30 days prior to surgery and reoperation. Further, in a study by Bengtson, et al., ${ }^{28)}$ there was no significant difference in the incidence of total 
Microvascular Anastomosis in Previous Treated Neck I Hyun SJ, et al.

Table 5. Univariative analysis of factors for cause of re-exploration

\begin{tabular}{|c|c|c|c|c|c|c|}
\hline \multirow{2}{*}{ Variable } & \multicolumn{2}{|c|}{ Venous congestion $(n=26)$} & \multicolumn{2}{|c|}{ Arterial crisis $(n=8)$} & \multicolumn{2}{|c|}{ Hematoma $(n=17)$} \\
\hline & $\mathrm{n}(\%)$ & p-value & $\mathrm{n}(\%)$ & $p$-value & $\mathrm{n}(\%)$ & $p$-value \\
\hline Age & & 0.221 & & 1.000 & & 0.927 \\
\hline$\leq 60(n=126)$ & $9(7.1)$ & & $4(3.2)$ & & $8(6.3)$ & \\
\hline$>60(n=148)$ & $17(11.5)$ & & $4(2.7)$ & & $9(6.1)$ & \\
\hline Sex & & 0.369 & & 0.443 & & 0.004 \\
\hline Male $(n=201)$ & $21(10.4)$ & & $5(2.5)$ & & $7(3.5)$ & \\
\hline Female $(n=73)$ & $5(6.8)$ & & $3(4.1)$ & & $10(13.7)$ & \\
\hline BMI & & 0.916 & & 0.382 & & 0.771 \\
\hline $\mathrm{BMI}>25(\mathrm{n}=61)$ & $6(9.8)$ & & $5(2.3)$ & & $3(4.9)$ & \\
\hline $\mathrm{BMI} \leq 25(\mathrm{n}=213)$ & $20(9.4)$ & & $3(4.9)$ & & $14(6.6)$ & \\
\hline Current smoker (in 28 days) & & 0.232 & & 1.000 & & 0.718 \\
\hline Yes $(n=39)$ & $6(15.4)$ & & $1(2.6)$ & & $3(7.7)$ & \\
\hline No $(n=235)$ & $20(8.5)$ & & $7(3.0)$ & & $14(6.0)$ & \\
\hline Cardiovascular disease & & 0.212 & & 1.000 & & 0.616 \\
\hline Yes $(n=96)$ & $12(12.5)$ & & $3(3.1)$ & & $5(5.2)$ & \\
\hline No $(n=178)$ & $14(7.9)$ & & $5(2.8)$ & & $12(6.7)$ & \\
\hline Diabetes & & 0.433 & & 0.645 & & 0.531 \\
\hline Yes $(n=51)$ & $3(5.9)$ & & $2(3.9)$ & & $4(7.8)$ & \\
\hline No $(n=223)$ & $23(10.3)$ & & $6(2.7)$ & & $13(5.8)$ & \\
\hline Reconstruction site & & 0.454 & & 0.101 & & 0.750 \\
\hline Oral cavity, oropharynx $(n=207)$ & $22(10.6)$ & & $6(2.9)$ & & $12(5.8)$ & \\
\hline Larynx, hypopharynx, esophagus $(n=46)$ & $2(4.3)$ & & $0(0)$ & & $4(8.7)$ & \\
\hline Maxilla $(n=15)$ & $2(13.3)$ & & $2(13.3)$ & & $1(6.7)$ & \\
\hline Ear $(n=6)$ & $0(0)$ & & $0(0)$ & & $0(0)$ & \\
\hline Donor site & & 0.379 & & 0.379 & & 0.459 \\
\hline ALTF/RFFF $(n=191)$ & $15(7.9)$ & & $4(2.1)$ & & $10(5.2)$ & \\
\hline Fibular/scapular/iliac crest flap ( $n=62)$ & $8(12.9)$ & & $3(4.8)$ & & $5(8.1)$ & \\
\hline LD/rectus abdominis flap $(n=19)$ & $3(15.8)$ & & $1(5.3)$ & & $2(10.5)$ & \\
\hline Jejunal flap (n=2) & $0(0)$ & & $0(0)$ & & $0(0)$ & \\
\hline Previous treatment at anastomosis site & & 0.050 & & 0.862 & & 0.004 \\
\hline No $(n=205)$ & $18(8.8)$ & & $6(2.9)$ & & $7(3.4)$ & \\
\hline RT/CCRT only $(n=35)$ & $1(2.8)$ & & $1(2.8)$ & & $4(11.1)$ & \\
\hline Neck dissection only $(n=11)$ & $2(18.2)$ & & $0(0)$ & & $2(18.2)$ & \\
\hline Neck dissection with RT/CCRT $(n=22)$ & $5(22.7)$ & & $1(4.5)$ & & $4(18.2)$ & \\
\hline Operation time (hour) & & 0.150 & & 0.114 & & 0.158 \\
\hline$>12$ hours $(n=43)$ & $7(16.3)$ & & $3(7.0)$ & & $5(11.6)$ & \\
\hline$\leq 12$ hours $(n=231)$ & $19(8.2)$ & & $5(2.2)$ & & $12(5.2)$ & \\
\hline Removed mass (large diameter) & & 0.204 & & 0.237 & & 0.008 \\
\hline$>10 \mathrm{~cm}(\mathrm{n}=32)$ & $5(15.6)$ & & $2(6.3)$ & & $6(18.8)$ & \\
\hline$\leq 10 \mathrm{~cm}(\mathrm{n}=242)$ & $21(8.7)$ & & $6(2.5)$ & & $11(4.5)$ & \\
\hline
\end{tabular}

BMI: body mass index, ALTF: anterolateral thigh flap, RFFF: radial forearm free flap, LD: latissimus dorsi flap, RT: radiation therapy, CCRT: concurrent chemoradiation therapy

free flap loss patients that received preoperative radiotherapy (5.3\%) and those who did not (5.0\%). In our analysis, microvascular anastomosis in terrains, where only RT had been performed, did not significantly increase the risk of flap failure or re-exploration. Although the risk of hematoma requiring re-exploration showed tendency to be higher than that of un- treated necks [OR=3.536 (95\% CI 0.979-12.767, $p=0.053)]$, the risk of venous congestion was not affected by RT.

In contrast, the risk of re-exploration was significantly higher in patients earlier treated with both neck dissection and RT in whom microvascular anastomosis is performed. However, in case of previous neck dissection and RT, although the 
Table 6. Logistic regression analysis of previous treatment for cause of re-exploration

\begin{tabular}{|c|c|c|c|c|c|c|}
\hline & \multicolumn{3}{|c|}{ Venous congestion } & \multicolumn{3}{|c|}{ Hematoma requiring re-exploration } \\
\hline & Crude OR & $95 \% \mathrm{Cl}$ & p-value & Crude OR & $95 \% \mathrm{Cl}$ & $p$-value \\
\hline No & Reference & & & Reference & & \\
\hline RT/CCRT only & 0.297 & $0.038-2.296$ & 0.245 & 3.536 & $0.979-12.767$ & 0.054 \\
\hline Neck dissection only & 2.309 & $0.463-11.512$ & 0.307 & 6.286 & $1.140-34.699$ & 0.035 \\
\hline Neck dissection with RT/CCRT & 3.056 & $1.009-9.255$ & 0.048 & 6.286 & $1.679-23.526$ & 0.006 \\
\hline
\end{tabular}

RT: radiation therapy, CCRT: concurrent chemoradiation therapy, OR: odds ratio, Cl: confidence interval

rate of flap failure was higher than in other groups, did not show any statistically significant difference in the risk of flap failure. In patients with a history of previous neck surgery, the formation of scar tissue and the vascular condition can affect the outcome of free flaps. In a study by Zhou, et al., ${ }^{20)}$ patients who had previous neck surgery $(21.4 \%)$ had significantly higher failure rates than those who did not $(2.7 \%)(p=0.007)$. In our study, the most common cause of re-exploration was venous congestion, and more venous congestion occurred in patients who received both neck dissection and radiotherapy before reconstruction surgery. Furthermore, hematoma was the second most common cause (33.3\%) of re-exploration, and previous neck dissection with or without RT influenced the development of hematoma requiring re-exploration. Previous neck dissection significantly increased the incidence of hematoma, which may be due to the restriction of drain position due to the pedicle and vascular condition affected by the previous surgery, or the scar tissue and the vascular condition may have been more affected by the postoperative enoxaparine.

As in any retrospective review, this study had some limitations. the database does not contain detailed information on the previous treatment, pedicle status, so we were unable to study these items together as variables.

In conclusion, the flap failure rate did not increase significantly with microvascular anastomosis in previously treated patients, but re-exploration was frequently performed in patients who previously received both neck dissection and RT. In particular, venous congestion and hematoma, the most common causes of re-exploration, were more common in patients who previously underwent both neck dissection and RT. Microvascular anastomosis in the context of previous RT did not increase the risk of flap failure or re-exploration and seemed to be performed safely. Therefore, microvascular anastomosis in previously treated necks, especially those previously treated with RT only, looks feasible without increasing the risk of flap failure. However, the surgeon should check the previous treatment history of the patient and be aware that microvas- cular anastomosis in the neck where both neck dissection and radiotherapy were performed earlier may be more likely to cause venous congestion or hematoma. In the case of patients with history neck dissection and radiotherapy, careful intraoperative hemostasis and technique are required, and postoperative management should also be taken care of with the higher possibility of re-exploration.

\section{Acknowledgments}

None.

\section{Author Contribution}

Conceptualization: Soon-Hyun Ahn. Data curation: Se Jin Hyun. Formal analysis: all authors. Funding acquisition: Soon-Hyun Ahn. Methodology: Se Jin Hyun. Project administration: Se Jin Hyun. Resources: Soon-Hyun Ahn. Supervision: Soon-Hyun Ahn. Validation: Soon-Hyun Ahn. Visualization: Se Jin Hyun. Writing - original draft: Se Jin Hyun. Writing — review \& editing: all authors.

\section{ORCIDs}

Soon-Hyun Ahn https://orcid.org/0000-0002-0759-6850

Se Jin Hyun https://orcid.org/0000-0002-2882-6491

\section{REFERENCES}

1) Adelstein DJ, Li Y, Adams GL, Wagner H Jr, Kish JA, Ensley JF, et al. An intergroup phase III comparison of standard radiation therapy and two schedules of concurrent chemoradiotherapy in patients with unresectable squamous cell head and neck cancer. J Clin Oncol 2003;21(1):92-8.

2) Forastiere AA, Goepfert H, Maor M, Pajak TF, Weber R, Morrison $\mathrm{W}$, et al. Concurrent chemotherapy and radiotherapy for organ preservation in advanced laryngeal cancer. N Engl J Med 2003; 349(22):2091-8.

3) Hamoir M, Schmitz S, Suarez C, Strojan P, Hutcheson KA, Rodrigo JP, et al. The current role of salvage surgery in recurrent head and neck squamous cell carcinoma. Cancers (Basel) 2018;10(8):267.

4) Lee SC, Shores CG, Weissler MC. Salvage surgery after failed primary concomitant chemoradiation. Curr Opin Otolaryngol Head Neck Surg 2008;16(2):135-40.

5) Bradford CR, Esclamado RM, Carroll WR, Sullivan MJ. Analysis of recurrence, complications, and functional results with free jejunal flaps. Head Neck 1994;16(2):149-54.

6) Shpitzer T, Neligan PC, Gullane PJ, Freeman JE, Boyd BJ, Rotstein LE, et al. Oromandibular reconstruction with the fibular free flap. Analysis of 50 consecutive flaps. Arch Otolaryngol Head Neck Surg 1997;123(9):939-44.

7) Truelson JM, Leach JL. Lateral thigh flap reconstruction in the 
head and neck. Otolaryngol Head Neck Surg 1998;118(2):203-10.

8) Urken ML, Weinberg H, Vickery C, Buchbinder D, Lawson W, Biller HF. Oromandibular reconstruction using microvascular composite free flaps. Report of 71 cases and a new classification scheme for bony, soft-tissue, and neurologic defects. Arch Otolaryngol Head Neck Surg 1991;117(7):733-44.

9) Yoo JY, Kim BK, Bae YJ, Rha KS, Park CI. Pharyngoesophageal reconstruction with forearm free flap. Korean J Otolaryngol 1990; 33(6):1193-7.

10) Jones NF. Postoperative monitoring of microsurgical free tissue transfers for head and neck reconstruction. Microsurgery 1988; 9(2):159-64.

11) Kwok AC, Agarwal JP. Unplanned reoperations after microvascular free tissue transfer: An analysis of 2,244 patients using the american college of surgeons national surgical quality improvement program database. Microsurgery 2017;37(3):184-9.

12) Thomas WW, Brant J, Chen J, Coblens O, Fischer JP, Newman JG, et al. Clinical factors associated with reoperation and prolonged length of stay in free tissue transfer to oncologic head and neck defects. JAMA Facial Plast Surg 2018;20(2):154-9.

13) Wenig BL, Keller AJ. Microvascular free flap reconstruction for head and neck defects. Arch Otolaryngol Head Neck Surg 1989; 115(9):1118-20.

14) Zhao EH, Nishimori K, Brady J, Siddiqui SH, Eloy JA, Baredes S, et al. Analysis of risk factors for unplanned reoperation following free flap surgery of the head and neck. Laryngoscope 2018;128(12): 2790-5.

15) Jones NF, Johnson JT, Shestak KC, Myers EN, Swartz WM. Microsurgical reconstruction of the head and neck: Interdisciplinary collaboration between head and neck surgeons and plastic surgeons in 305 cases. Ann Plast Surg 1996;36(1):37-43.

16) Baek CH, Park W, Choi N, Gu S, Sohn I, Chung MK. Free flap outcome of salvage surgery compared to primary surgery for head and neck defects: A propensity score analysis. Oral Oncol 2016;62: 85-9.

17) Colen LB, Stevenson A, Sidorov V, Potparic Z, Pacelli E, Searles J, et al. Microvascular anastomotic thrombosis in experimental diabetes mellitus. Plast Reconstr Surg 1997;99(1):156-62.

18) Valentini V, Cassoni A, Marianetti TM, Mitro V, Gennaro P, Ialongo
$\mathrm{C}$, et al. Diabetes as main risk factor in head and neck reconstructive surgery with free flaps. J Craniofac Surg 2008;19(4):1080-4.

19) Nakatsuka T, Harii K, Asato H, Takushima A, Ebihara S, Kimata $Y$, et al. Analytic review of 2372 free flap transfers for head and neck reconstruction following cancer resection. J Reconstr Microsurg 2003;19(6):363-8; discussion 369

20) Zhou W, Zhang WB, Yu Y, Wang Y, Mao C, Guo CB, et al. Risk factors for free flap failure: A retrospective analysis of 881 free flaps for head and neck defect reconstruction. Int J Oral Maxillofac Surg 2017;46(8):941-5.

21) Pattani KM, Byrne P, Boahene K, Richmon J. What makes a good flap go bad? A critical analysis of the literature of intraoperative factors related to free flap failure. Laryngoscope 2010;120(4):71723.

22) Haughey BH, Wilson E, Kluwe L, Piccirillo J, Fredrickson J, Sessions D, et al. Free flap reconstruction of the head and neck: Analysis of 241 cases. Otolaryngol Head Neck Surg 2001;125(1):10-7.

23) Wong AK, Joanna Nguyen T, Peric M, Shahabi A, Vidar EN, Hwang $\mathrm{BH}$, et al. Analysis of risk factors associated with microvascular free flap failure using a multi-institutional database. Microsurgery 2015;35(1):6-12.

24) Fried MP. The effects of radiation therapy in microvascular anastomoses. Laryngoscope 1985;95(7 Pt 2 Suppl 37):1-33.

25) Benatar MJ, Dassonville O, Chamorey E, Poissonnet G, Ettaiche M, Pierre CS, et al. Impact of preoperative radiotherapy on head and neck free flap reconstruction: A report on 429 cases. J Plast Reconstr Aesthet Surg 2013;66(4):478-82.

26) Herle P, Shukla L, Morrison WA, Shayan R. Preoperative radiation and free flap outcomes for head and neck reconstruction: A systematic review and meta-analysis. ANZ J Surg 2015;85(3):121-7.

27) Tall J, Björklund TC, Skogh AC, Arnander C, Halle M. Vascular complications after radiotherapy in head and neck free flap reconstruction: Clinical outcome related to vascular biology. Ann Plast Surg 2015;75(3):309-15.

28) Bengtson BP, Schusterman MA, Baldwin BJ, Miller MJ, Reece GP, Kroll SS, et al. Influence of prior radiotherapy on the development of postoperative complications and success of free tissue transfers in head and neck cancer reconstruction. Am J Surg 1993;166(4): 326-30. 